\title{
SELECTIVE FLOTATION OF FOSSIL RESIN FROM WESTERN COAL
}

DOE Contract DE-AC22-90PC90178

A Special Report Comprising:

Monthly Report for December 1991

Monthly Report for January 1992

Monthly Report for February 1992

Monthly Report for March 1992

Monthly Report for April 1992

\section{And}

DOE/FC/90178--T6

$D \times 92017925$

N

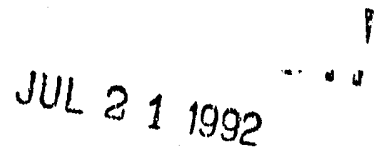

Quarterly Reports for Dec 1, 1991 to Feb. 29, 1992

Submitted by: Gordon F. Jensen, Director

Utah Engineering Experimental Station

University of Utah

Salt Lake City, Utah 84112

and

Jan D. Miller, Professor

Department of Metallurgical Engineering University of Utah

Salt Lake City, Utah 84112

$\operatorname{Mar} 20,1992$

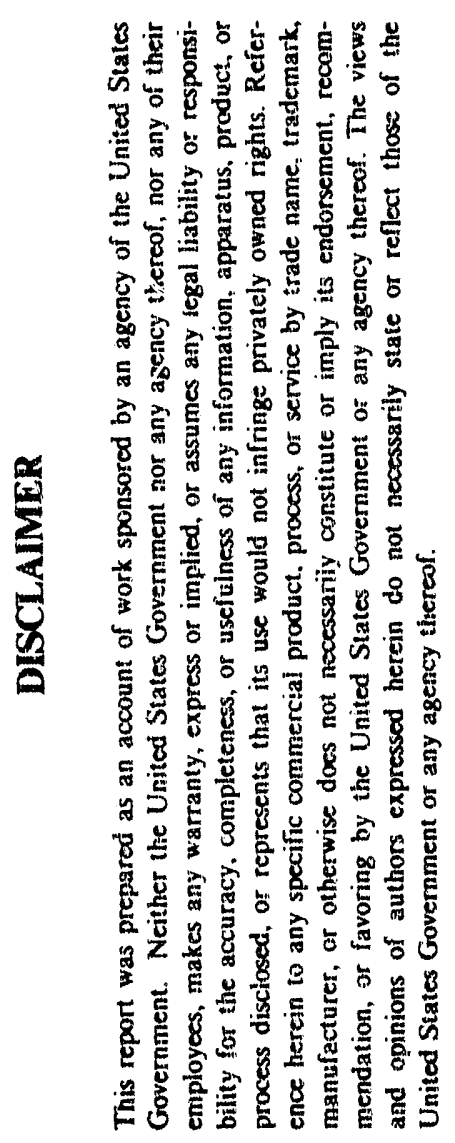


This is a special report which comprises several monthly reports and one quarterly reports.

Due 10 a variety of reasons including unanticipated variations in process strategy evaluation, delays in technical/theoretical analysis, change of personne! at Advanced Processing Technologies, Inc., and some uncontrollable factors for obtaining data, these reports were delayed for submission. However, the projects has been quite successful and many contributions have been made towards the eventual development of a fossil resin industry in Utah. In summary, the test program has demonstrated that:

1) technically, the new flotation technologies discovered at the University of Utah and then improved upon by Advanced Processing Technologies, Inc. provide a highly efficient means to selectively recover fossil resin from coal. The proof-ofconcept continuous flotation circuit resulted in fossil resin recovery with the same separation efficiency as was obtained from laboratory bench-scale testing (more than $80 \%$ recovery at about $80 \%$ concentrate grade); and

2) econonically, the selective flotation process has been shown to be sufficiently profitable to justify the development of a fossil resin industry based on this new flotation process.

The proof-of-concept testing has resulted in significant interest from several coal mining companies and has sparked the desire of local and state government to cstablish a fossil resin industry in the Wasatch Plateau coal field. In this view, the results from the current proof-ofconcept testing program have been successful.

This special report provides theoretical and analytical data on some surface chemistry work pertinent to fossil resin characturization, and other efforts carried out during the past months. University of Utah has requested a three-month no-cost extension of the contract in December 1991 and the request has then been subsequently approved by DOE. After this special report, University of Utah will submit a final report covering entire project. The draft of final report is in place and will be submitted to DOE after reviewing and receiving critique from 
pertinent persons.

\section{Contact Angle Moasurement}

The contact angle of resinite and coal in warer were measured on a resin coated aluminum plate (for resinite) and a polished section (for coal) with a Rame-Hart contact angle goniometer using both sessile-drop and captive-bubble methods. The polished surface of the coal was prepared by first cutting with the Isomet ${ }^{\text {TM }}$ Low Speed Saw made by BUEHLER and then followed by polishing the surface with Buehler $\# 600$ polishing paper. Since no such large resinite sample could be found, the surface of resinite was prepared by solution evaporation to deposit resinite on an aluminum plate with a thickness of about $0.3 \mathrm{~mm}$. The resin solution was prepared by taking $1 \mathrm{~g}$ of composite resinite ( $-400 \mathrm{mesh})$ and $10 \mathrm{ml}$ of toluene in a $50 \mathrm{ml}$ hask and shaking for 2 hours at room temperature. After dissolution, $2 \mathrm{ml}$ of the resin solution was placed onto the aluminum plate two or three times. A uniform coating of resinite was formed by carefully shaking the plate by hand to distribute the solution and then the coated plate was dried in a vacuum oven at $70^{\circ} \mathrm{C}$ for 24 hours to remove the solvent by evaporation. After preparation of both coal and resinite surfaces, the contact angle for each sample was measured in deionized water using both the sessile-drop and captive-bubble methods at room temperature. The advancing contact angle was measured after adding a liquid drop onto a drop already on the surface. An average of 10 measurements were made for the contact angles on both sides of the drop for both resinite and coal surfaces. In the case of contact angle measurement by the captive-bubble method, more than six small air bubbles about $2 \mathrm{~mm}$ in diameter were introduced at the coal-water or fossil resin-water interface as the surface was immersed in deionized water. 
In each case, the values of contact angle and its standard deviation were obtained from at least ten measurements.

The contact angle values of the resinite and coal measured by both the sessile-drop method and the captive-bubble method along with the standard deviations at the $95 \%$ confidence level are listed in Table 1. As seen from Table 1 the contact angle for resinite is greater than that for coal as measured by both sessile-drop and captive-bubble methods. These results agree with other results reported in the literature. It indicates that the resinite surface is more hydrophobic than the coal surface. Since the sessile-drop method provides the advancing contact angle while captive-bubble method gives only the receding contact angle, the contact angle obtained by the sessile-drop method is observed to be greater than that obtained by the captivebubble method. Conditions for the flotation and the measurement of contact angle by the captive-bubble method involve similar pheromena, and it is believed that the difference in the contact angles of resinite and coal obtained by the captive-bubble method truly represent their hydrophobic difference with respect to flotation. Since the difference between the captive-bubble contact angles for resinite and coal is small $\left(\Delta=6.4^{\mathrm{D}}\right)$, it is expected that the difference in their flotation response is also small.

Table 1. The contact angles for resinite and coal

Contact Angle (degrees)

$\begin{array}{lcc}\text { Sample } & \text { Sessile-Drop } & \text { Captive-Bubble } \\ \text { Resinite } & 84.5 \pm 6.6 & 46.1 \pm 6.9 \\ \text { Coal } & 57.1 \pm 7.2 & 39.7 \pm 3.8\end{array}$




\section{Zeta Potential Measurement}

The zeta potential of both resinite and coal samples was determined using the electrophoretic method at room temperature. In this determination, about $0.1 \mathrm{~g}$ of wet-ground (minus 400 mesh) resinite or coal was mixed with $200 \mathrm{ml}$ of $1 \times 10^{-3} \mathrm{M} \mathrm{NaNO}_{3}$ solution in a 500 $\mathrm{ml}$ beaker. The suspensions then were adjusted to a desired $\mathrm{pH}$ value using analytical grade $\mathrm{HCl}$ and $\mathrm{NaOH}$ at room temperature. The measurements of zeta potential were carried out the next day (after 30 hours) in order to allow for equilibration of the resinite and coal surfaces. The reported $\mathrm{pH}$ value is the final $\mathrm{pH}$ measured just prior to electrophoresis.

Zeta potentials of resinite and coal particles in suspension were determined with a Zeta Meter System 3.0 manufactured by Zeta-Meter Inc. An electrophoresis cell (GT-2 circular cell) was used for the measurement. More than ten measurements were made at each $\mathrm{pH}$ value and the average zeta potential obtained was reported in order to minimize the experimental error and variation.

In order to study the electrokinetic behavior of resinite and coal particles, zeta polential measurements for both resinite and coal have been determined as a function of $\mathrm{pH}$ at roon temperature. A plot of zeta potential against the suspension $\mathrm{pH}$ for resinite and coal is given in Figure 1. The zeta potential for both resinite and coal decreases with an increase in suspension pH, which suggests that the $\mathrm{H}^{+}$may be potential-determining. The variation of zeta potential with $\mathrm{pH}$ was found to be similar for both resinite and coal particles with resinite showing a more negative charge (by about $10 \mathrm{mv}$ ). This indicates that the charging mechanism which occurs at the surface of either resinite or coal is similar. The IEPs for resinite and coal were fourd to occur at about pH 3.5 and 3.7, respectively. In other words, if the suspension pH is greater than 


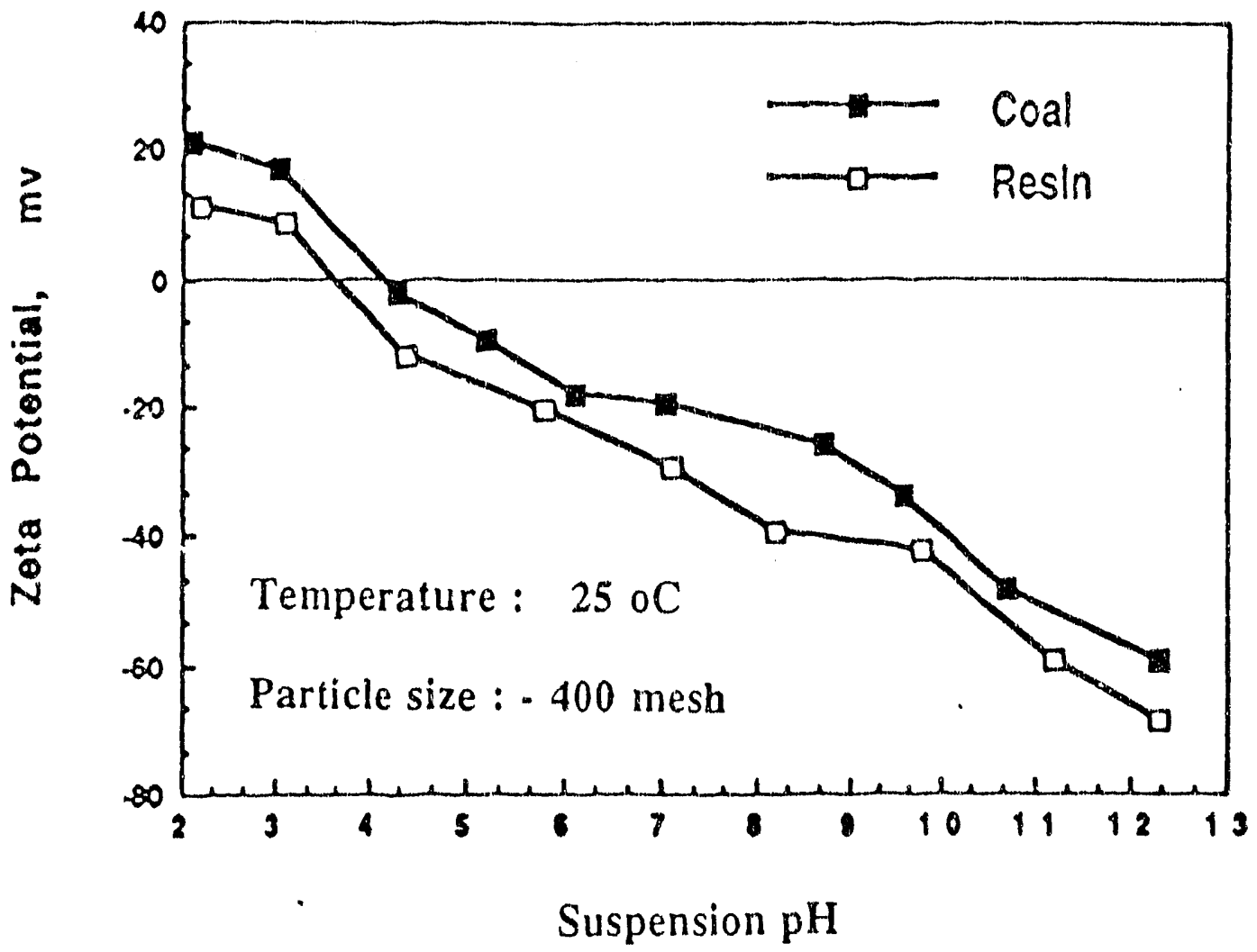

Figure 1. Electrokinetic behavior of resinite and coal particles as a function of suspension $\mathrm{pH}$ 
pH 4 , both the resinite and coal surface will be negatively charged. At neutral pH the zeta potentials of resinite and coal were found to be about -25 and $-18 \mathrm{mv}$, respectively.

\section{Film Flotation}

Film flotation tests were conducted at room temperature by using methanol-water solutions, which were mixed in different proportions so that the surface tension of the resulting solution varied from $22.5 \mathrm{dyne} / \mathrm{cm}$ (for pure methanol) to $72.5 \mathrm{dyne} / \mathrm{cm}$ (for pure water). The tests were performed in glass vessels similar to separatory funnels. About $0.3 \mathrm{~g}$ sample $(100 \times 200$ mesh fraction) of either resinite or coal was gently sprinkled onto the surface of the methanol/water solutions of different surface tensions. The particles either remained at the liquid/air interface or were wet and sunk into the liquid depending on the hydrophobicity of the particles and the surface tension of methanol/water solution. In each glass vessel, depending on the surface tension of the solution therein, both the particles still floating at the liquid/air interface (hydrophobic or none-wetted particles) and the particles which had sunk into the liquid (hydrophilic or wetted particles) were collected, dried, and weighed respectively. After film flotation, the weight fraction of non-wetted particles was calculated for each methanol/water solution. A plot of percent none-wetted fraction versus the surface tension of the solution for both resinite and coal was thus obtained. From the curve the mean critical surface tension of wetting, at which $50 \%$ particles remain hydrophobic was determined for both resinite and coal.

The wettability or hydrophobicity of resinite and coal was evaluated by film flotation tests using methanol-water solutions with different compositions to change the surface tension from 72.4 to 22.4 dyne $/ \mathrm{cm}$. The partition curves of resinite and coal as obtained from film flotation 
are plotted as a function of surface tension of methano-water solution and are presented in Figure 2. It is seen from Figure 2 that the partition curve for both resinite and coal have similar shapes, however that of coal is slightly shifted to higher surface tension values. The mean critical surface tensions of wetting for both resinite and coal, at which $50 \%$ particles remain as hydrophobic, were determined from the plot and are given in Table 2.

The low values for the critical surface tensions of wetting indicates a fairly high level of surface hydrophobicity. Resinite, thus exhibits a higher level of hydrophobicity than that for the coal surface. The slightly higher hydrophobicity of the resinite surface was demonstrated by the flotation response of the resinite particles, when compared to associated coal particles. However, due to the very small difference $(\Delta=6$ dyne $/ \mathrm{cm})$ in their mean critical surface tension of wetting and also due to small difference in contact angle $\left(\Delta=6.4^{\circ}\right)$ obtained by captive-bubble method, the selective flotation of resinite from coal is rather limited. Some coal particles also float into the froth product along with the resinite, and the effectiveness of resinite separation from coal is poor by conventional flotation.

In general, both resinite and coal exhibit a relatively low mean critical surface tension of wetting (below 41 dyne $/ \mathrm{cm}$ ) which indicates that they are marginally hydrophobic. Due to small differences in their zeta potentials and hydrophobicities, aggregation or heterocoagulation will take place between resinite and coal particles in suspension to minimize their interfacial free energy at the resinitewwater and coal-water interfaces. Such an aggregation and/or heterocoagulation can cause fine coal particles to float along with resinite into the froth phase, and consequently a poor grade in resin concentrate is obtained by conventional flotation. 


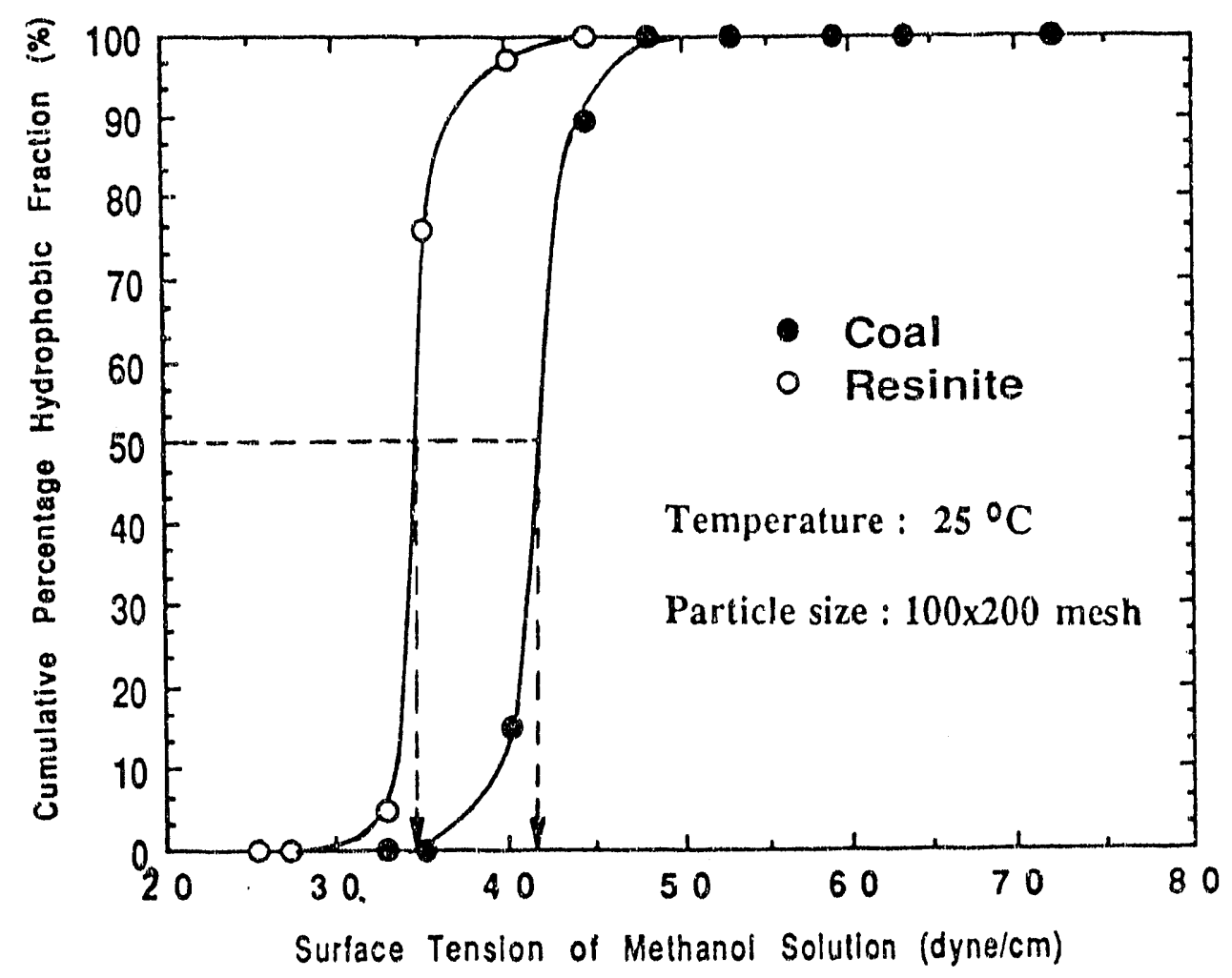

Figure 2. Film flotation partition curves of resinite and coal. 
Table 2. The mean critical surface tension of wetting for both coal and resinite

Sample $(100 \times 200$ mesh) Mean Critical Surface Tension of Wetting (dyne $/ \mathrm{cm})$

Resinite

35

Coal

41

\section{Hallimond Tube and Vacuum Tube Flotation}

For Hallimond tube flotation tests, in each experiment, $1 \mathrm{~g}$ of resinite or coal sample (16x65 mesh) was conditioned in a $200 \mathrm{ml}$ beaker with $50 \mathrm{ml}$ deionized water for about 30 minutes at room temperature. After conditioning, the suspension was allowed to stand for 3 days to let the resinite or coal surface fully hydrate. Then, the suspension was transferred into the Hallimond lube where it was conditioned for another three minutes. Compressed air was introduced through the gas inlet at a rate of $260 \mathrm{ml} /$ minute for 20 minutes. After flotation, the float and none-float materials were recovered, dried, and weighed for mass balance. In the case of vacuum flotation, one gram sample (16x65 mesh) was conditioned in $50 \mathrm{ml}$ of deionized water in the vacuum flotation cell for 5 minutes by hand-shaking. The cell level was then adjusted to the desired level with a constant amount of deionized water and the cell connected to a vacuum system with a $1000 \mathrm{ml}$ trap. The vacuum flotation was carried out for two minutes and the pressure was maintained at about $12 \mathrm{~cm} \mathrm{Hg}$. Subsequently, the float and none-float fraction were separated, filtered, dried and weighed to obtain the float yield for both the resin and the coal samples.

The results obtained from reagentless Hallimond tube and Vacuum tube flotation tests for 
different resin types and the coal sample are given in Figure 3. It is clear that the reagentless flotation response or yield was observed to follow the order of yellow resin $>$ amber resin $>$ light-brown resin $>$ dark-brown resin $>$ coa! as revealed from both Hallimond tube and Vacuum tube flotation yield. For example, in the case of vacuum tube flotation almost all of the yellow resin (97.6\%) floated while a much smaller amount of dark-brown resin (34.8\%) and hardly any coal (11.5\%) floated in two minutes. This indicates that the surface hydrophobicity increases as the resin color changes from dark brown to yellow. Coal, in comparison with the resins, is shown to have a relatively low hydrophobicity. Therefore, yellow resin has the highest hydrophobicity and is the easiest and fastest to float while dark-brown resin has lowest hydrophobicity and is more difficult and slowest to float (Figure 3). It appears that in order to increase the dark-brown resins recovery by flotation, either more flotation time or the addition of flotation reagents will be required. However, by increasing either flotation time or reagent dosage, additional coal particles will also float along with the resin particles into the froth phase, and again the concentrate grade would be lowered.

Further, it should also be pointed out that the bubble attachment strength between the airbubble and resin type decreases with a change in color of the resin in the order of yellow resin $>$ amber resin $>$ light-brown resin $>$ dark-brown resin. Such a bubble-particle attachment behavior was clearly observed during both vacuum tube and Hallimond tube flotation tests. Particles of light-brown and dark-brown resin attached to an air bubble were easily separated (detached) from the air bubble due to turbulence and/or collision with the walls of the tube and were found to remain at the bottom of the flotation cell. 
Reagentless Hallimond Tube and Vacuum Tube Flotation Response
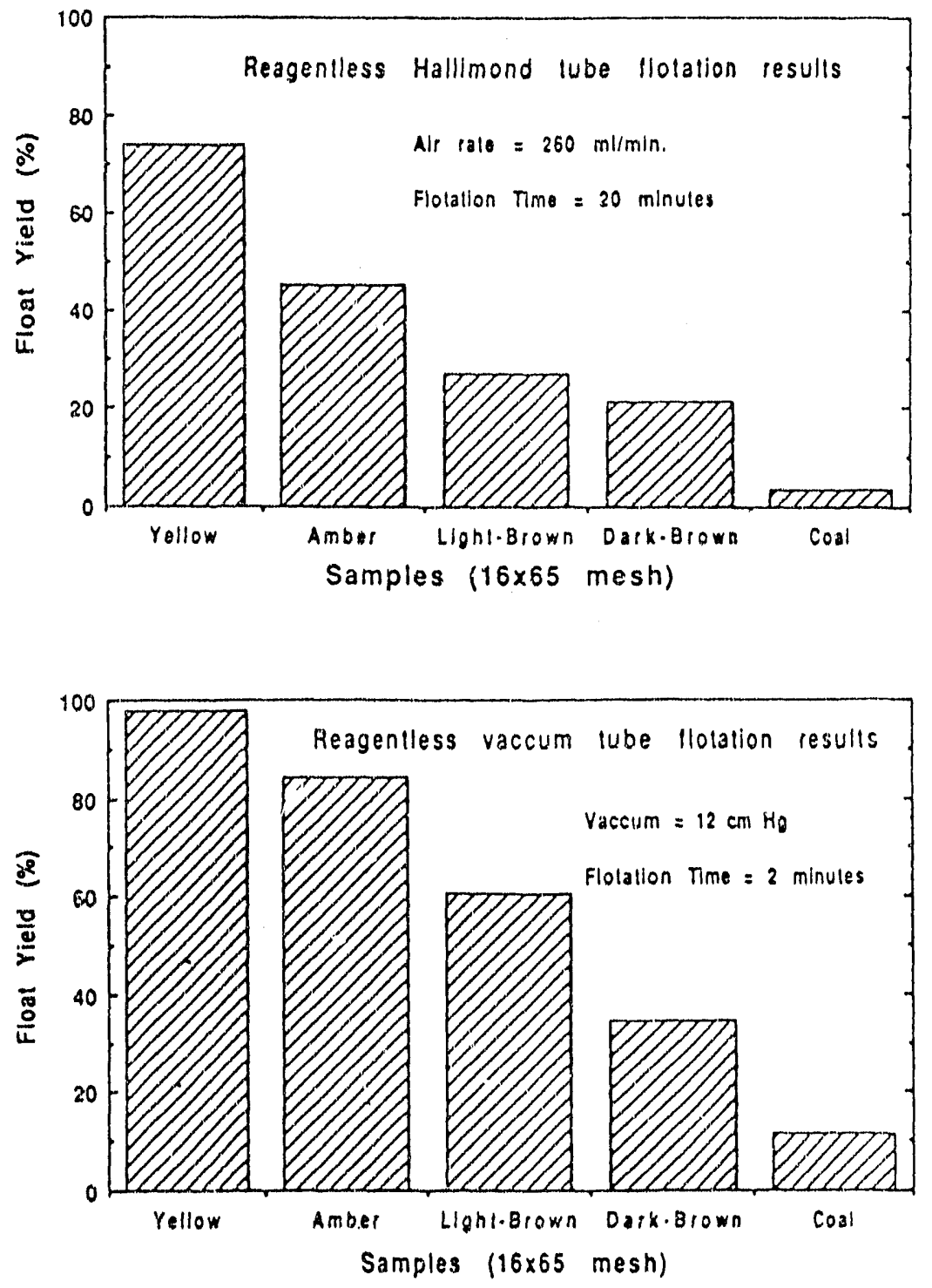

Figure 3. Resultts of reagentless Hailimond tube and vacuum tube flotation tests of four resin types and the coal sample from the Wasatch Plateau coal field. 


\section{Time Release Bench-Scale Pesinile Flotation}

To determine the bench-scale flotation response of resin types with respect to flotation time, time release bench-scale flotation of resinite from the Wasatch Platenu coal was carried out in a 2-liter Denver flotation cell. In this regard, a rougher concentrate (-28 mesh) was used as feed material for these experiments. This thotation concentrate was obtained from the US Fuels plant at Hiawatha when it was operated by CPS and was found to contain about $45 \%$ hexane soluble resin. The sample was washed to remove (wet screening) all minus 400 mesh tines and the original reagents used a the flotation in order to obtain this rougher concentrate. About 200 $\mathrm{g}$ of such a prepares sample was placed into the flotation cell with 2 liters of fresh water. The suspension was conditioned at $1500 \mathrm{rpm}$ for 3 minutes after each addition of frother ard time interval. Butanol pentanol was gradually added into the suspension at each desired time interval. The resinite fotation was carried out at $1200 \mathrm{rpm}$ ard the air flowrate was maintained at $4 \mathrm{l} / \mathrm{min}$. The resinite concentrate was collected at each time interval respectively and the collected producs as well as the final coal reject were filtered, dried, and analyzed. Another time release resinite tlotation test was also carried out following the same procedure except the prepared sample was subjected to wet grinding in a ceramic ball mill for 30 minutes prior to flotation.

The time ielease bench-scale flotation experiments were conducted for the rougher concentrate (with and without grinding), and the results are given in Figure 4. As is seen from the flotation response in Figure 4 without grinding the cumulative resinite grade decreases slightly from $94 \% 1086 \%$ while the cumulative resin recovery increases significantly from $33 \%$ $1096 \%$ with an increase in flotation time from about 1 minute to 6.7 minutes. After grinding, the cumulative resinite grade decreases from $97 \%$ to $83 \%$ while the cumulative resin recovery 
increases dramatically from $22 \%$ to $99.6 \%$ with an increase in flotation time from about 1 minutes to 6.7 minutes. Since the feed sample for time release flotation was a rougher concentrate containing about $45 \%$ hexane soluble resin, the flotation results are much better than those results obtained by flotation from low grade feed samples. It should also be pointed out that the color of the froth phase was observed to change during the time release flotation sequence from yellow at the beginning of flotation to a gray then to a dark-gray during the final stages of flotation. This gives additional evidence that light resin (yellow or amber) inore hexane soluble resin floats faster and more easily than the dark resin (light-brown and darkbrown). In the later stage of flotation some coal particles reporting to the froth phase was noticed.

Finally it should be mentioned that a suitable grinding may be necessary to improve resinite separation efficiency as indicated in Figure 4. It seems that grinding does liberate, to some extent, the finely dispersed coal colloid inclusions found in the dark resins. A resinite concentrate containing about $90 \%$ hexane soluble resin with $88 \%$ resin recovery can be obtained after 30 minutes of wet grinding while only about $80 \%$ resin recovery could be obtained at a comparable resin grade without grinding. 
A. Without grinding.

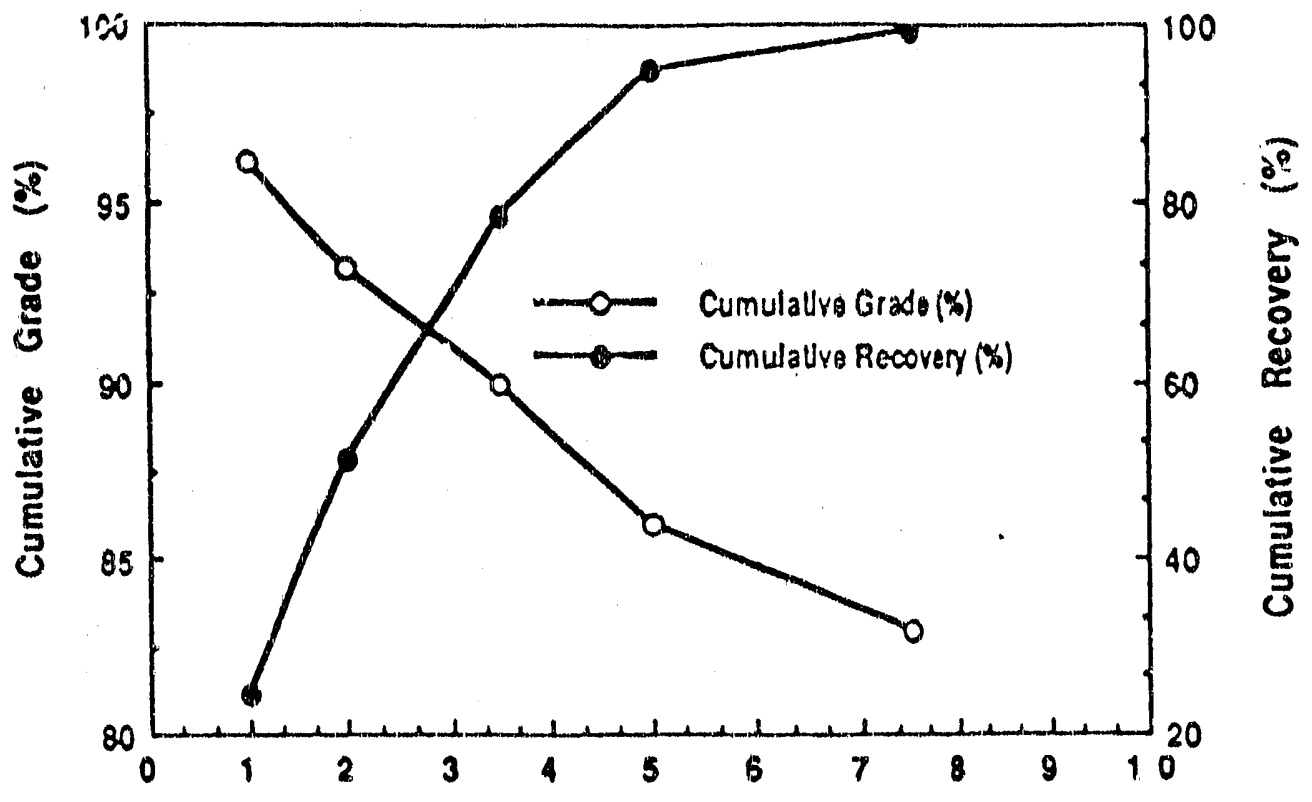

B. After 30 minutes grinding

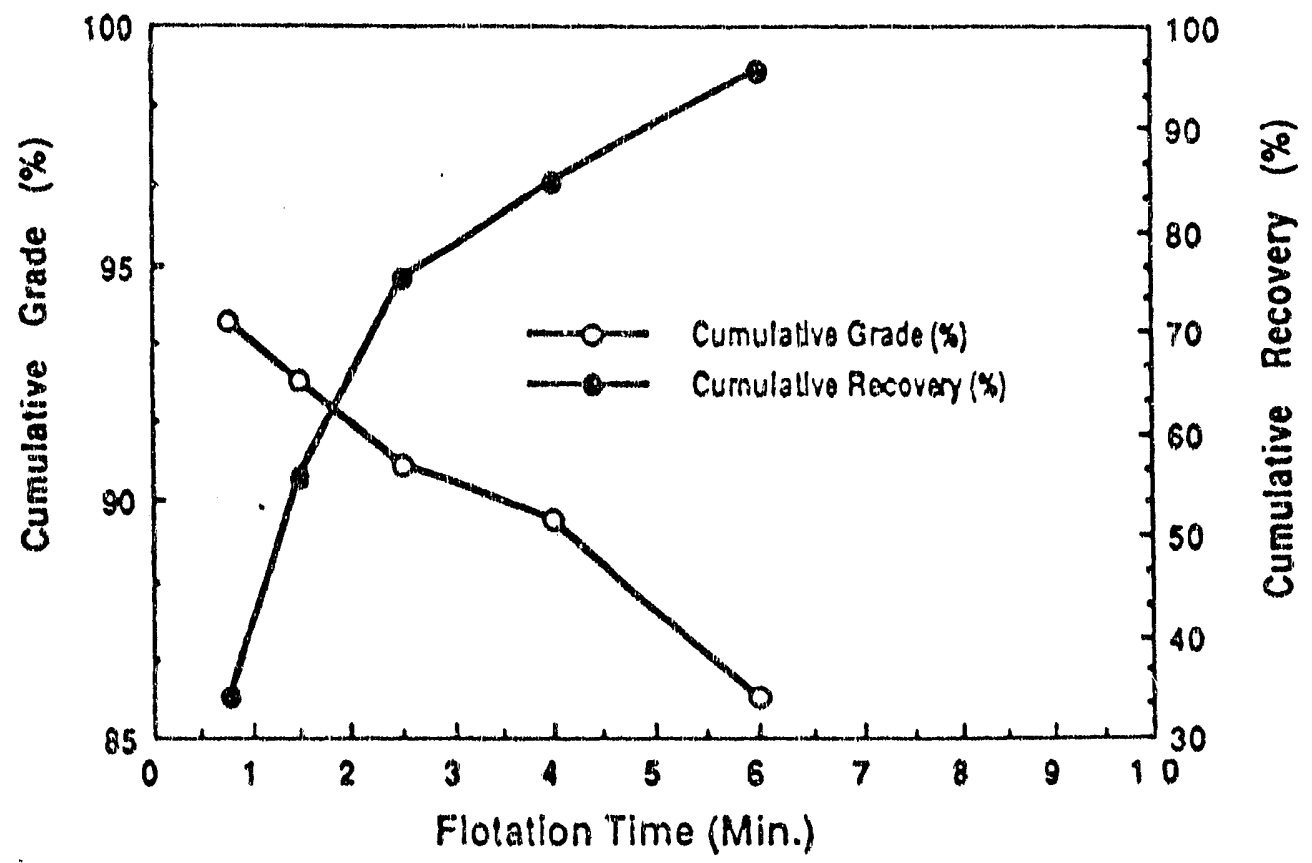

A -... Without grinding; B ... After 30 minutes grinding; which contains 


\section{$\underline{\text { Particle/Particle Interaction }}$}

a). Single Phase System

In the case of the single phase system, about $250 \mathrm{~g}$ of either the composite resinite or the coal sample (-28 mesh) and $1000 \mathrm{ml}$ deionized water were taken into a ceramic ball mill for wetgrinding for 1 hour. The wet-ground fine resinite or coal suspension was filtered and the filtered cake was used for sedimentation tests. The sedimentation was carried out with a $100 \mathrm{ml}$ graduated cylinder. About $2 \mathrm{~g}$ of the filtered cake and $100 \mathrm{ml}$ of desired $\mathrm{pH}$ solution were put into the cylinder and then carefully mixed by hand agitation using a glass rod for about 5 minutes. Once the suspension was ready for sedimentation, the cylinder was put in place, and the midline height of the suspension was recorded as a function of time. The suspension $\mathrm{pH}$ reported was then measured after the sedimentation tests had been completed. A plot of midline height of each resinite or coal suspension was thus obtained as a function of time for different $\mathrm{pH}$ values.

b). Binary System

Binary systems consisting of a mixture of the resinite and coal samples were studied at different $\mathrm{pH}$ values in a 1 -liter flotation cell for the analysis of particle-particle interaction. About $50 \mathrm{~g}$ of composite resinite ard the same amount of the coal sample (both minus 28 mesh) together with $500 \mathrm{ml}$ of deionized water were placed in the 2-liter Denver flotation cell. Analytical grade hydrochloric acid and calcium hydroxide were used for $\mathrm{pH}$ adjustment. This suspension was then stirred for 10 minutes at $900 \mathrm{rpm}$ after each pH adjustment. A few drops of the suspension were withdrawn from the flotation cell and placed on a thin glass slide and then covered with a cover slip for microscopic examination with transmitted light at $100 x$ 
magnification.

The settling curves of fine resinite and coal suspensions ( -400 mesh) obtained by batch sedimentation tests at different $\mathrm{pH}$ values are shown in Figure 5. As seen from the curves in Figure 5, the extent of sedimentation increases with a decrease in suspension $\mathrm{pH}$, the lower the suspension $\mathrm{pH}$ the faster the settling velocity. For $\mathrm{pH}$ values greater than 9.6 for coal and 7.4 for resinite, the settling velocity was found to be extremely slow so that almost no change in midline height is observed even after two hours. These results show that the rate of sedirnentation strongly depends on the suspension ply.

Sedimentation results also provide a further indication that many fine resinite or coal particles at lower $\mathrm{pH}$ values form aggregates which cause an increase in settling velocity. On the other hand, at high $\mathrm{pH}$ values the fine resinite and coal particles repel one another due to increased electrosiatic repulsion forces and a stable dispersion is formed.

The lower the $\mathrm{pH}$, the weaker the repulsive forces between resin and coal particles and the suspension will be coagulated; the higher the $\mathrm{pH}$, the stronger the repulsion and the suspension will be dispersed. The critical $\mathrm{pH}$ between coagulation and dispersion was found to be $\mathrm{pH}$ 8.6-9.6 for the fine coal suspension, and $\mathrm{pH}$ 5.4-7.4 for the fine resinite suspension. The lower critical $\mathrm{pH}$ for the resinite suspension is probably due to its larger negative charge at any given $\mathrm{pH}$ value.

For binary system, the particle-particle interaction has been examined microscopically at different $\mathrm{pH}$ values to determine if heterocoagulation occurs between resinite ( -28 mesh) and coal (-28 mesh). Microphotographs of the coal/resinite suspension are presented in Figure 6 for different $\mathrm{pH}$ values. As seen from Figure 6, at low $\mathrm{pH}(\mathrm{pH}=3.2$ and $\mathrm{pH}=5.1)$, massive 

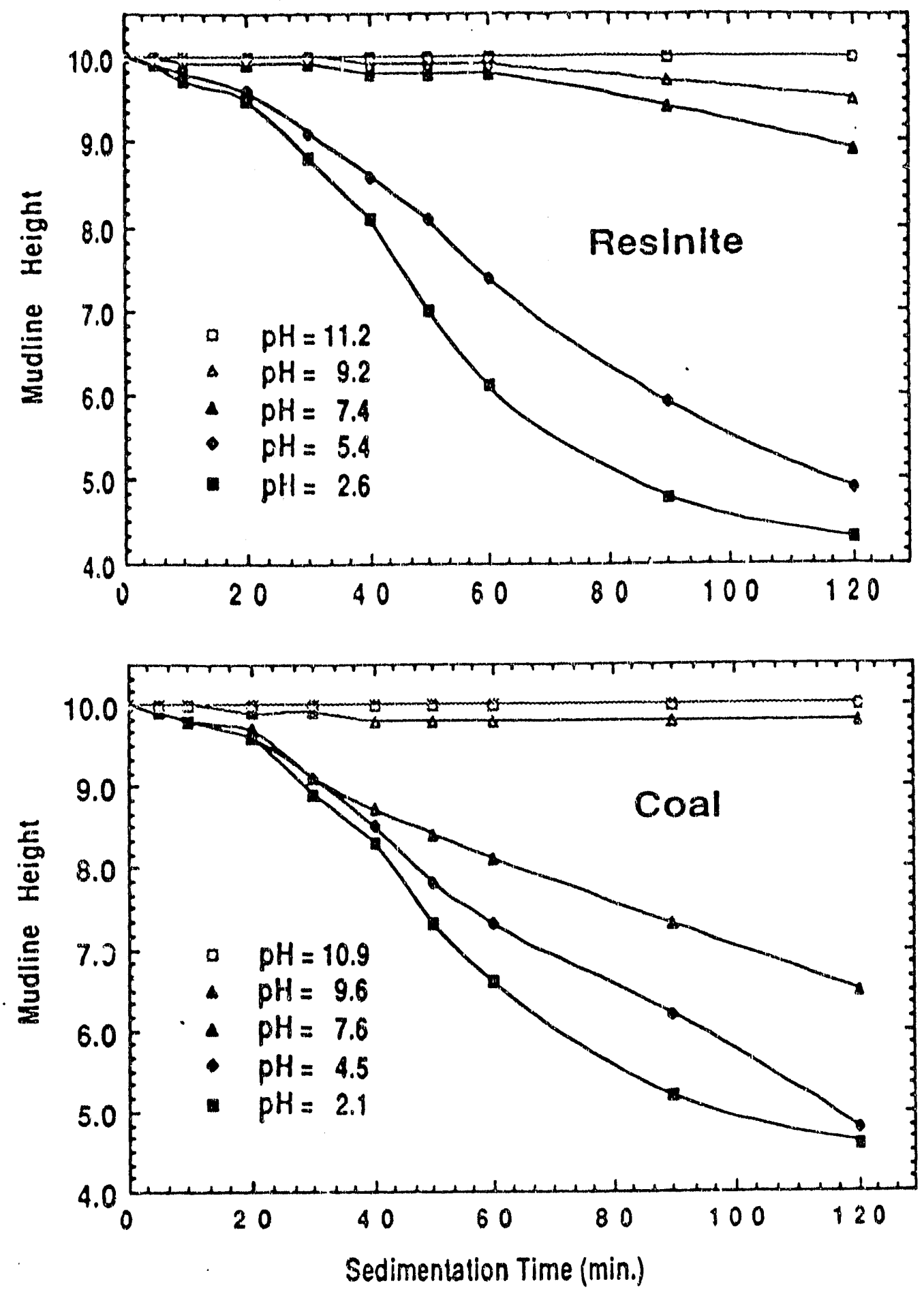

Figure 5. Effect of $\mathrm{pH}$ on the sedimentation of fine resinite and coal suspensions. 


\section{Suspension $\mathrm{pH}$}
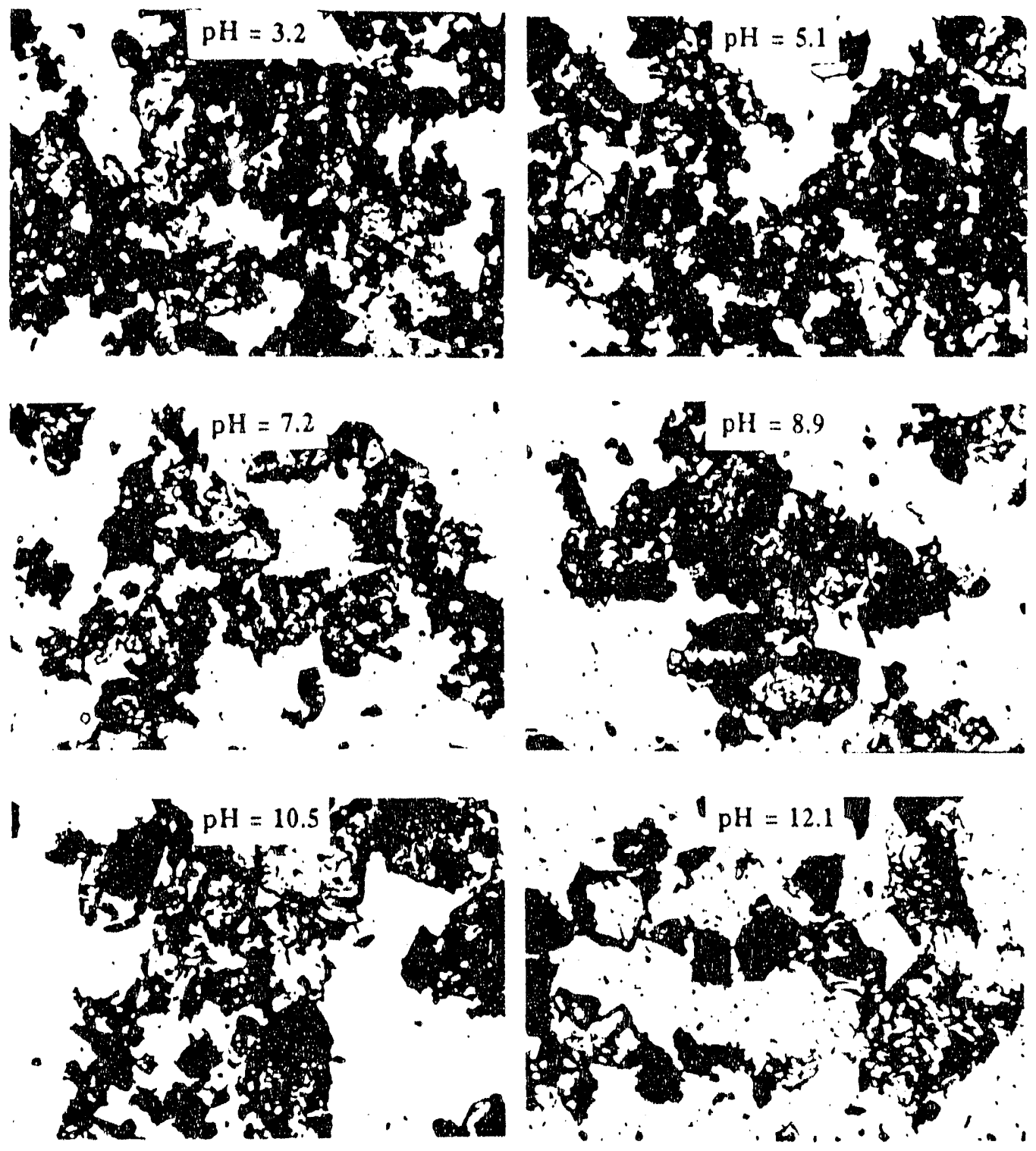

Figure 6. Microphotographs of interparticle behavior of resinite/coal suspensions at different $\mathrm{pH}$ values. 
aggregates of resinite and coal particles are observed in suspension. As the $\mathrm{pH}$ increases $(\mathrm{pH}=$ 7.2 and $\mathrm{pH}=8.9$ ), resinite and coal particles begin to become more dispersed. Finally at higher pH values $(\mathrm{pH}=10.5$ and $\mathrm{pH}=12.1)$, the resinite and coal particles are almost completely dispersed.

At lower pH values (lower surface charge), the repulsive force provided by electrostatic repulsion between resinite and coal particles is smaller than the attractive forces provided by van der Waal forces between resinite and coal particles, and the heterocoagulation between resinire and coal particles takes place. With an increase in suspension $\mathrm{pH}$ values (with a corresponding increase in surface charge) the electrostatic repulsive force between resinite and coal particles becomes greater and greater while the attractive force remains unchanged at a particular separation distance. Eventually, at high $\mathrm{pH}$ values the electrostatic repulsive force becomes dominant, and the resinite and coal particles in suspension will repel each other and the sy'stem becomes dispersed as observed from the microphotographs in Figure 6.

\section{Surface Precipitation/Adsorption Experiments}

\section{Sample Preparation}

In order to examine the reaction of calcium hydroxide $\left(\mathrm{Ca}(\mathrm{OH})_{2}\right)$ at the surfaces of both resinite and coal particles at different $\mathrm{pH}$ values the samples were first demineralized. This was accomplished by taking $50 \mathrm{~g}$ of wet-ground fine resinite or coal sample (minus $400 \mathrm{mesh}$ ) in a $500 \mathrm{ml}$ teflon beaker containing $200 \mathrm{ml}$ of $10 \%$ mixture of analytical grade hydrochloric and hydrofluoric acids $(1: 1)$ and heating on a hot-plate to about $80^{\circ} \mathrm{C}$ for about 2 hours. After demineralization the sample was washed with deionized water at least eight times. The ash 
content of the demineralized resinite sample could not be detected while the ash content of the demineralized coal had been reduced to $0.4 \%$. These demineralized samples were used to study the nature of the reaction of calcium hydroxide. A saturated solution of calcium hydroxide (analytical grade) was used to adjust the $\mathrm{pH}$ of either resinite or coal suspension. About 3 grams of demineralized resinite or coal sample and a certain volume of $\mathrm{Ca}(\mathrm{OH})_{2}$ saturated solution (volume depended on the desired $\mathrm{pH}$ ), together with deionized water were added to a $2000 \mathrm{ml}$ beaker. The suspension was then agitated with a magnetic stirrer for 2 hours to let $\mathrm{Ca}(\mathrm{OH})_{2}$ react at the surface of the resinite or coal particles. After reaction the pH value of the suspension was measured (equilibrium $\mathrm{pH}$ ), and the suspension was vacuum filtered with Whatman \#1 filter paper. The filtered resinite or coal cake was placed into a vacuum oven for drying at $70^{\circ} \mathrm{C}$ for 24 hours and the dried sample was then analyzed by FTIR and XPS spectroscopy.

\section{a). XPS Spectra}

The XPS spectra of oxygen (1s), calcium (2p) and carbon (1s) for resinite and coal samples at $\mathrm{pH} 11.4$ are given in Figure 7. As seen from Figure 7, one single $\mathrm{O}$ (1s) peak at 525 (eV), two Ca (2p) peaks at $344(\mathrm{eV})$ and $340(\mathrm{eV})$, and one $\mathrm{C}(1 \mathrm{~s})$ peak at $277(\mathrm{eV})$ are observed from the XPS spectra of resinite and coal samples at $\mathrm{pH} \mathrm{11.4.} \mathrm{The} \mathrm{Ca} \mathrm{(2p)} \mathrm{XPS} \mathrm{spectra} \mathrm{for}$ resinite and coal samples at different $\mathrm{pH}$ values are presented in Figure 8. It can be seen that the signal intensity of calcium (2p) for both resinite and coal is found to increase with an increase in $\mathrm{pH}$, and the signal intensity of $\mathrm{Ca}(2 \mathrm{p})$ for coal is greater than that for resinite at each specified pH. At pH 7.6 (neutral $\mathrm{pH}$ ) no calcium peak is observed for either sample. The relative amounts of oxygen, calcium, and carbon present in the samples can be estimated by 

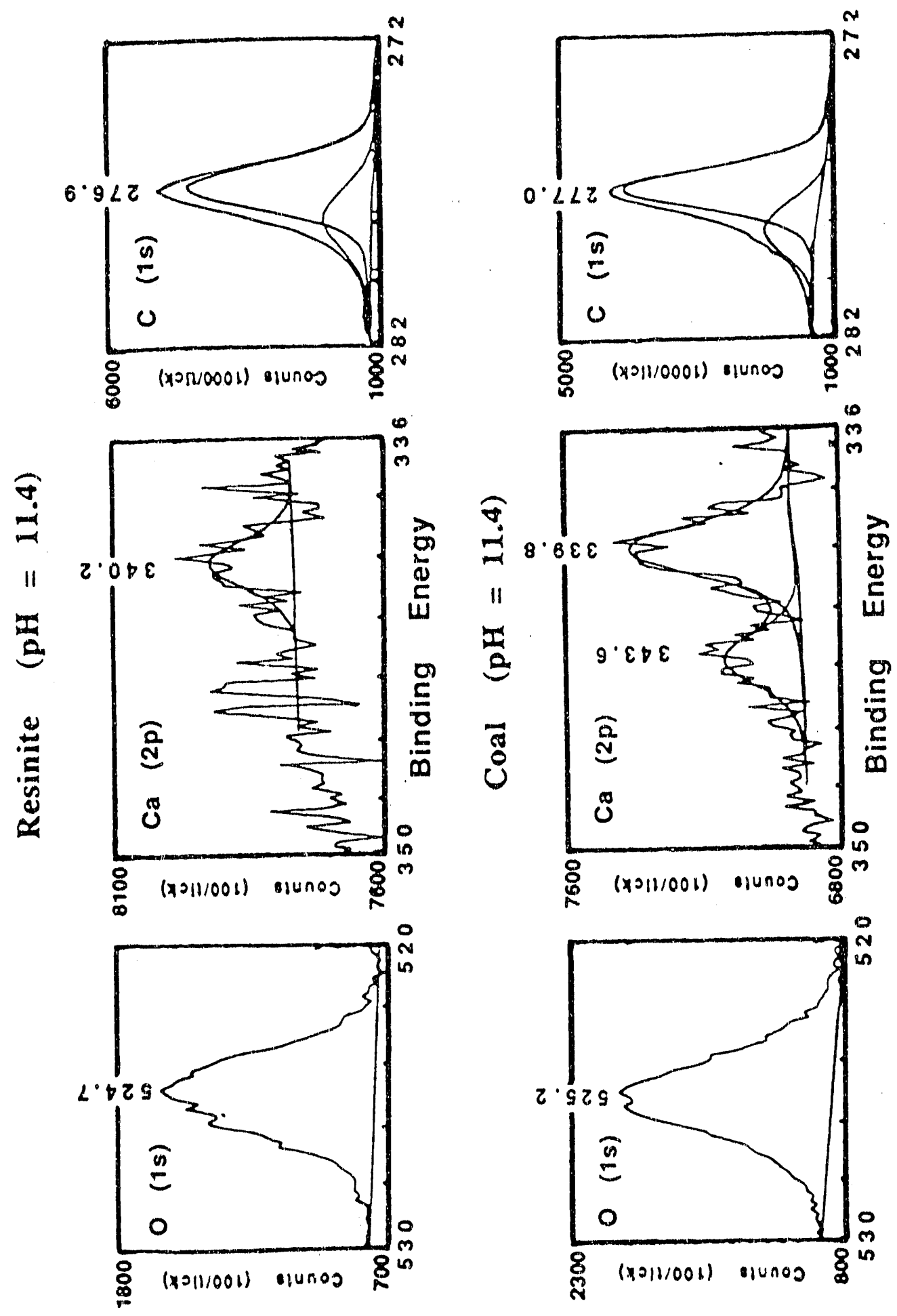

Figure 7. XPS spectra of surface oxygen (1s), calcium (2p), and carbon (1s) for resinite and coal samples at $\mathrm{pH} 11.4$. 

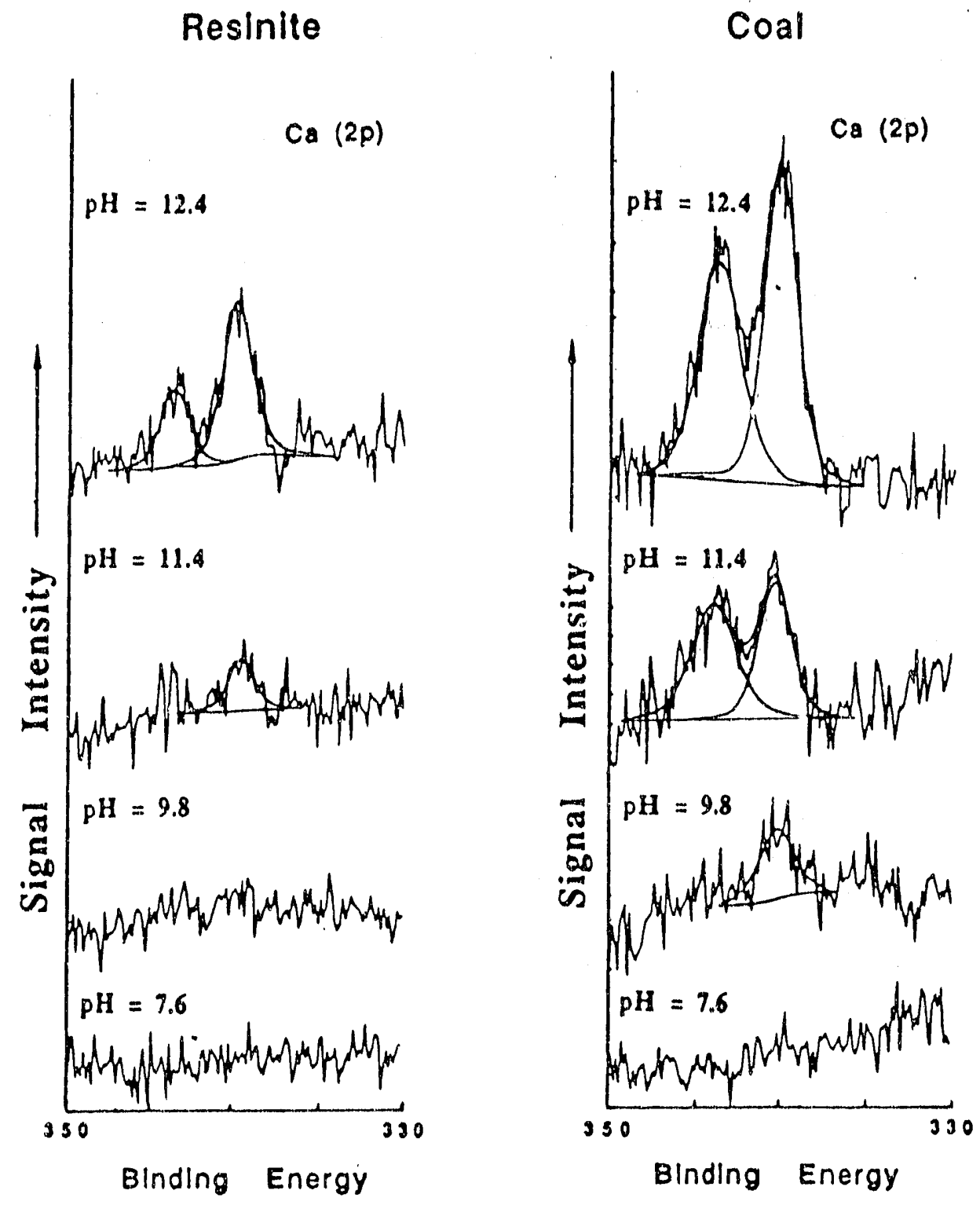

Figure 8. Surface $\mathrm{Ca}(2 \mathrm{p}) \mathrm{XPS}$ spectra of resinite and coal samples at different $\mathrm{pH}$ values. 
integrating the area under their respective peaks in the XPS spectra. The effect of $\mathrm{pH}$ on the relative surface composition for both resinite and coal samples as obtained from their XPS analyses are presented in Figure 9. As seen from Figure 9, it is clear that similar trends are observed in coal and resinite with respect to their relative suriace compositions as a result of changes in $\mathrm{pH}$. The relative carbon content is found to decrease with an increase in $\mathrm{pH}$, while the relative content of oxygen and calcium is found to increase with an increase in $\mathrm{pH}$. These findings indicate that calcium adsorption at both resinite and coal surfaces occurs for suspensions of $\mathrm{pH}$ greater than 9. This adsorption is found to increase with an increase in $\mathrm{pH}$, especially for $\mathrm{pH}$ values greater than 11 . Greater calcium adsorption is observed at the coal surface than at the resinite surface for the same $\mathrm{pH}$, and such an adsorption occurs at the coal surface even at lower $\mathrm{pH}$ values while on resinite surface it occurs only at higher $\mathrm{pH}$, as shown in Figures 8 and 9 . The calcium adsorption at the resinite and coal surfaces might occur by one of two possible ways, namely columbic adsorption or chemical reaction. First, the electrostatic interaction between the negatively charged surface of resinite or coal particles (see Figure 9) and calcium ions $\left(\mathrm{Ca}^{2+}\right)$ may lead to calcium adsorption. In either case, the higher the $\mathrm{pH}$, the more negative charge on the surfaces and the more $\mathrm{Ca}^{2+}$ ions that will adsorb. Second, it is also possible that chemical reaction occurs between the surface functional groups (especially oxygen-functional groups including $-\mathrm{OH},-\mathrm{COOH},>\mathrm{C}=\mathrm{O},-\mathrm{C}-\mathrm{O}$ ) at the resinite or coal surface and calcium ions from solution to result in a complex or salt formation. Since there are more oxygen functional groups at the coal surface than at the resinite surface, more $\mathrm{Ca}^{2+}$ ions could be chemically accommodated at the coal surface than at the resinite surface. In addition, $\pi$-electrons from the aromatic components of the coal might also promote such a reaction and stabilize the surface 


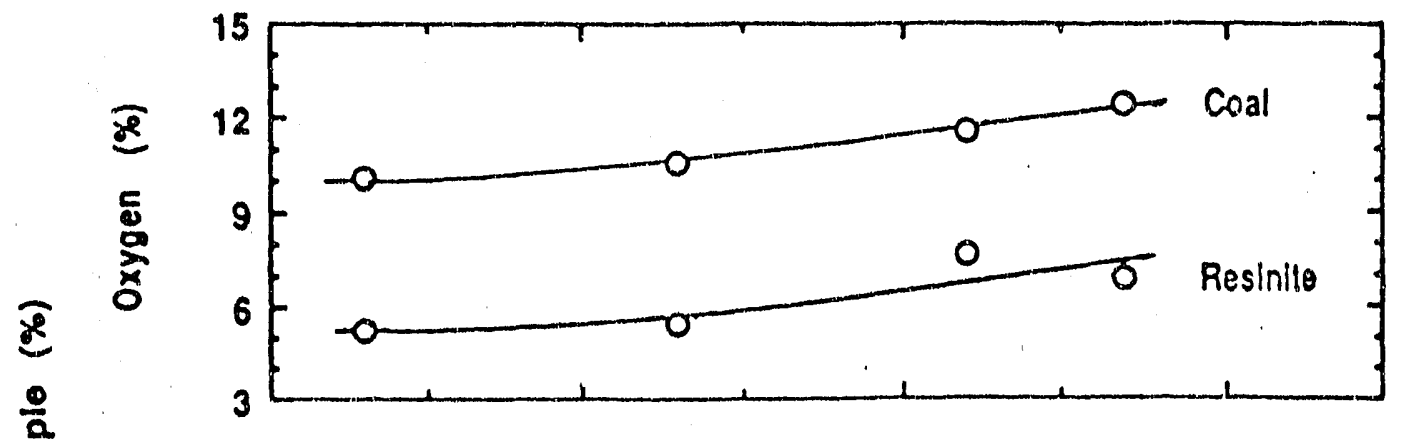

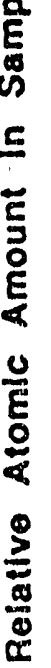
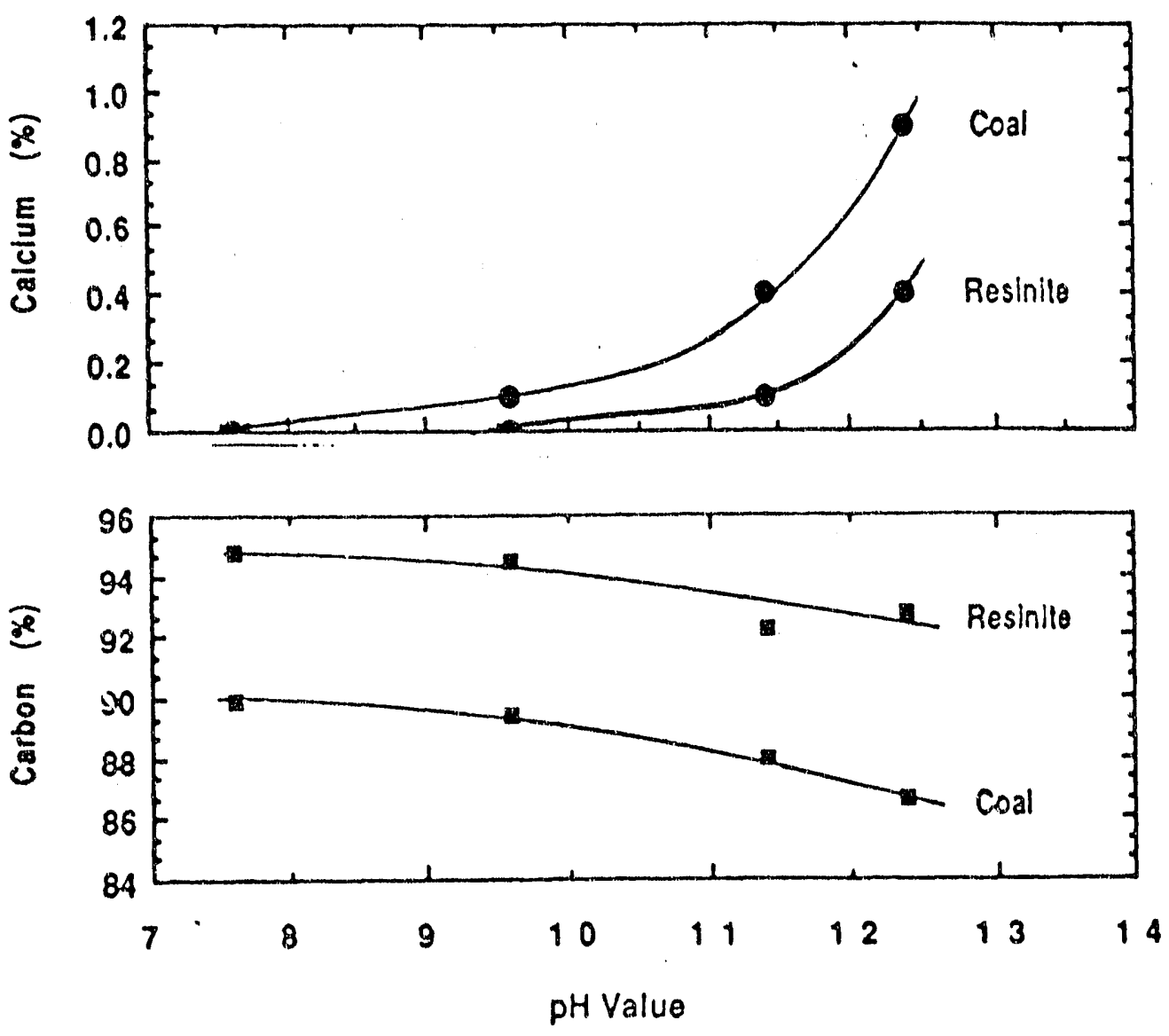

Figure 9. The relative atomic amount of $\mathrm{O}, \mathrm{Ca}$, and $\mathrm{C}$ at the resinite and coal surface (100 $\AA$ depth of penetration) as obtained from their XPS spectra as a function of $\mathrm{pH}$. 
complex.

Calcium is strongly hydrated and after adsorption would create hydrophilic sites at the coal and resinite surface. When this occurs, the coal and resinite particles will be difficult to float compared to their natural state. The coal particles which adsorb more calcium are expected to become more hydrophilic than resinite particles at a given $\mathrm{pH}$. Thus coal particles are dispersed and selectively depressed during resinite flotation from coal at high $\mathrm{pH}$.

\section{b). FTIR Analysis}

The effect of $\mathrm{Ca}(\mathrm{OH})_{2}$ conditioning on the surface of cual and resinite particles was also determined by DRIFT-FTIR spectroscopy for different $\mathrm{pH}$ values. The spectra of $\mathrm{Ca}(\mathrm{OH})_{2}$ conditioned coal and resinite at three different $\mathrm{pH}$ values are presented in Figure 10. These spectra were generated by subtracting the spectrum of the sample prepared at neutral $\mathrm{pH}$ $(\mathrm{pH}=7.6)$ from the spectrum of the sample prepared at the desired $\mathrm{pH}$ as identified in the Figure

8. Such a subtraction will provide the most direct information on the precipitation/adsorption of calcium at the resinite and coal surfaces.

$\mathrm{Ca}(\mathrm{OH})_{2}$ in solution could give rise to species such as $\mathrm{Ca}^{2+}, \mathrm{Ca}(\mathrm{OH})^{+}, \mathrm{Ca}(\mathrm{OH})_{2}$, the concentrations of which depend on such variables as $\mathrm{pH}$ and their equilibrium conditions. Potentially all these species could adsorb on coal and resinite surfaces. But the occurrence of absorbance bands in the subtracted spectra at $704 \mathrm{~cm}^{-1}, 863 \mathrm{~cm}^{-1}, 1450 \mathrm{~cm}^{-1}, 1788 \mathrm{~cm}^{-1}, 2503 \mathrm{~cm}^{\text {. }}$ , and $3582 \mathrm{~cm}^{-1}$ suggest that the adsorbed species react with the carboxylic groups on the coal and resinite surfaces to form carboxylates (Figure 11). Further, the adsorption of calcium species on the surfaces of both resinite and coal was found to increase with $\mathrm{pH}$ as revealed from the 

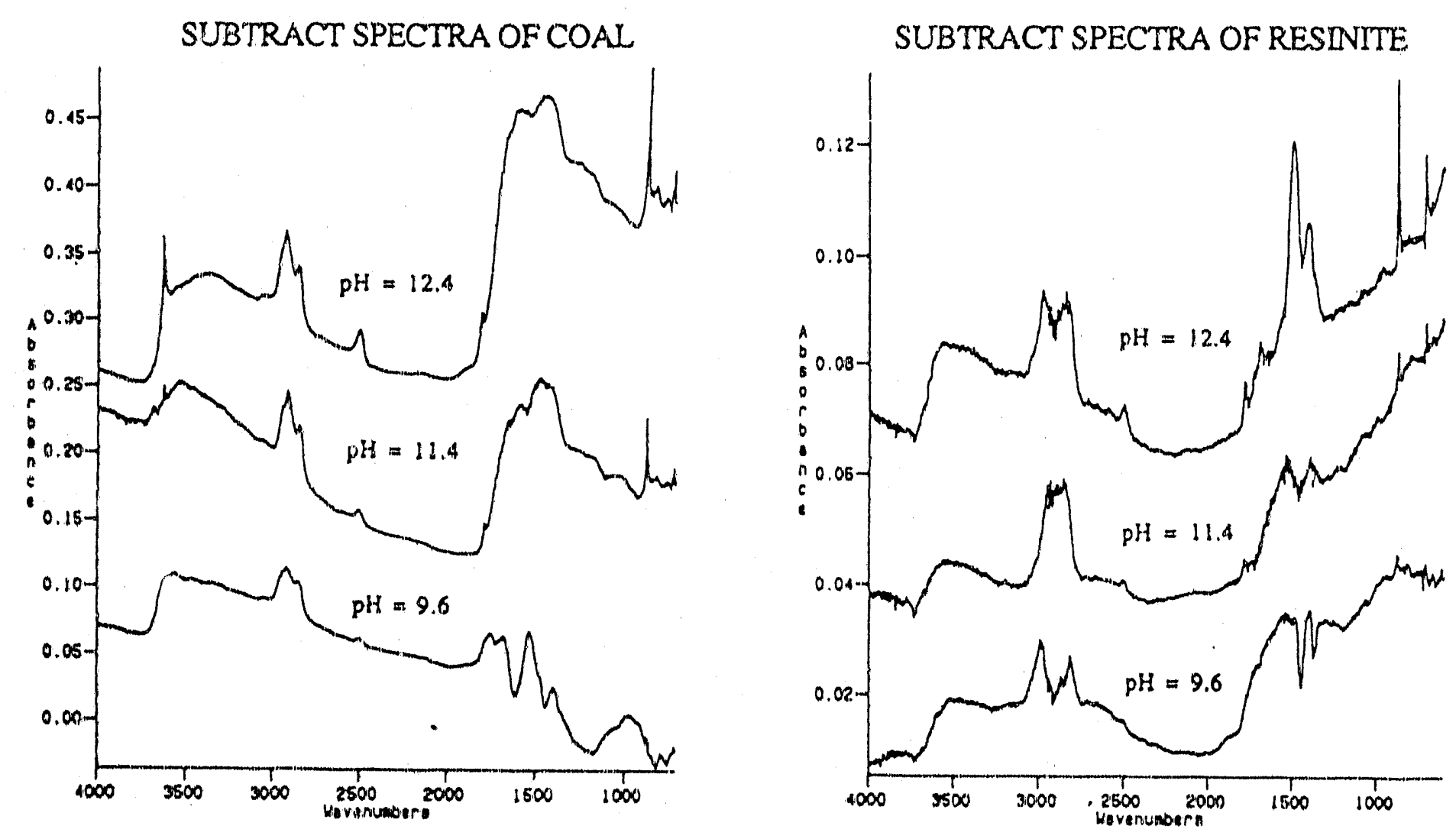

Figure 10. Subtracted spectra obtained from DRIFT-FTIR analysis for resinite and coal samples conditioned with $\mathrm{Ca}(\mathrm{OH})_{2}$ at different suspension $\mathrm{pH}$. 


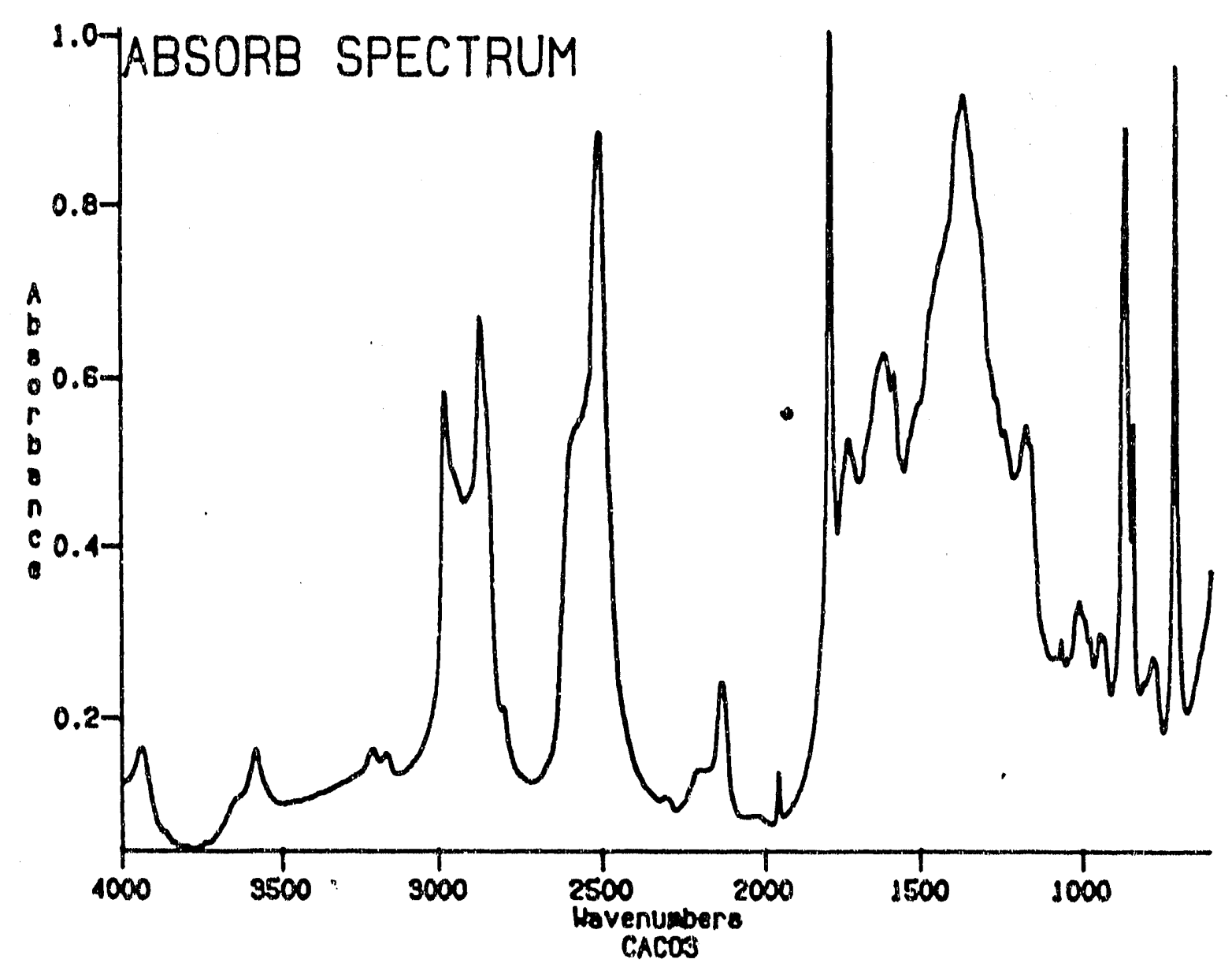

Figure 11. DRIFT-FTIR spectrum of analytical grade calcium carbonate. 
intensity' of the above specified absorbance bands. As was concluded from XPS spectra, the subtracted FI'IR spectra of coal indicates higher adsorption of calcium species at the coal surface than at the resinite surface.

\section{Decommissioning}

Advanced Processing Technologies, Inc. has successfully finished decommissioning of the flotation circuit used for the proof-of-concept testing, which is identified as Task 10 in the contract. Rented equipment has been returned, constructed equipment/facilities has been dismantled and DOE owned equipment (flotation machines) has been stored for future use. 

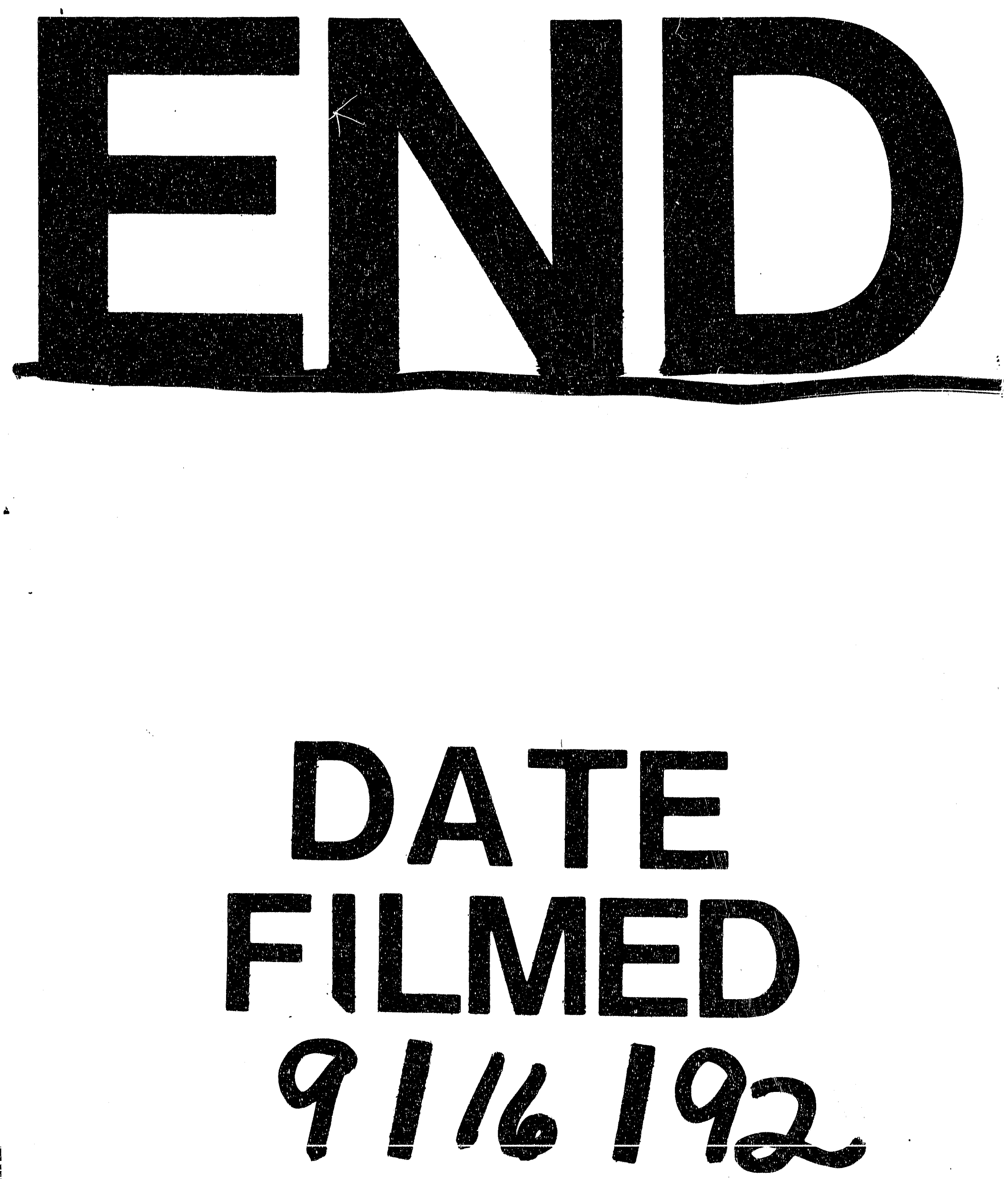
$=0$
$=$
$=$
$=$
$=$ 